Department of Public Health and Primary Care, Behaviour and Heath Research Unit, University of Cambridge, Cambridge, UK

2 Department of Psychological Medicine, King's College London, London, UK

Correspondence to: T M Marteau tm388@cam.ac.uk Cite this as: BMJ 2020;370:m2913 http://dx.doi.org/10.1136/bmj.m2913 Published: 26 July 2020

\section{Is risk compensation threatening public health in the covid-19 pandemic?}

Unfounded concerns about risk compensation threaten public health when they delay the introduction
of protective measures such as wearing of face coverings, argue Theresa Marteau and colleagues Eleni Mantzari, ${ }^{1} \mathrm{G}$ James Rubin, ${ }^{2}$ Theresa M Marteau

Wearing face coverings, particularly in shared indoor spaces, is now mandated or recommended in more than 160 countries to reduce transmission of SARS-CoV-2. ${ }^{1}$ Cloth face coverings, if correctly worn, can reduce transmission of the virus as part of a set of protective measures, including maintaining physical distance from others and good hand hygiene..$^{1-5}$

Although uncertainties remain about the size of effect from including cloth face coverings in a package of measures for reducing transmission, the weight of evidence from laboratory and observational studies justifies their use. ${ }^{1-5}$ Greenhalgh and colleagues recently urged policy makers to encourage the wearing of face masks because the risks are minimal and the potential impact substantial. ${ }^{6}$

Concerns have been raised, however, that wearing face coverings might lead people to forgo other protective behaviours. ${ }^{7-11}$ Early in the pandemic, the World Health Organization warned that wearing medical masks when not indicated can "create a false sense of security that can lead to neglecting other essential measures such as hand hygiene practices." This response has been variously described as risk compensation, false reassurance, risk homeostasis, moral licensing, rebound, or negative spillover effect.

How justified are these concerns about risk compensation in the context of face coverings to reduce transmission of SARS-CoV-2? We start by examining the evidence for risk compensation in relation to other health threats.

\section{Risk compensation and other health threats}

Risk compensation is a term widely used but with different interpretations. The central idea is that people have a target level of risk they are comfortable with and they adjust their behaviour to maintain that risk level. ${ }^{12}$ In this conceptualisation, risk compensation is synonymous with the concept of risk homeostasis. It famously has its origins in opposition to driver safety regulations, with an early proponent arguing that regulations were "at best useless and at worst counterproductive." This was based on the assumption that people offset any gain in safety with an increase in risky behaviour. ${ }^{13}$ Others have used the term risk compensation to describe any change in risk behaviour, with no assumption that an increase in risky behaviour completely offsets the benefits of a safety measure. ${ }^{14}$

At an individual level, risk compensation is commonplace. For example, people run for longer to offset an eagerly anticipated indulgent meal. A cyclist may wear a helmet to cycle at speed. However, from a population perspective, risk compensation should be judged by the average change in an outcome from which the impact of any compensating behaviour can be inferred to follow an intervention-for example, bike injuries and fatalities after mandated wearing of bike helmets.

Four interventions are often cited as leading to risk compensation: wearing of bike or ski helmets (purportedly leading to riskier cycling or skiing), circumcision to prevent HIV infection, HIV pre-exposure prophylaxis, and HPV vaccination (all purportedly leading to increased unprotected sexual activity). The results of the most recent systematic reviews for each intervention provide no evidence for an increase in any outcome deemed to reflect risk compensation (box 1)..$^{15-19}$ For HPV vaccination, the opposite effect was found: those vaccinated were less likely to engage in unprotected sexual behaviour, as measured by self-report and rates of sexually transmitted infection. ${ }^{19}$

\section{Box 1: What systematic reviews conclude about risk} compensation

\section{Helmet wearing}

- "In sum, this systematic review found little to no support for the hypothesis bicycle helmet use is associated with engaging in risky behaviour" 15

- "The use of safety helmets also does not appear to increase the risk of compensation behavior as compared to non-helmeted participants in skiing and snowboarding" 16

Pre-exposure prophylaxis to prevent HIV infection

- "One concern about PrEP [pre-exposure prophylaxis] is that its use may lead to persons at risk of HIV acquisition not using condoms or engaging in other behaviors that could increase their risk of STIS [sexually transmitted infections] (ie, behavioral risk compensation). In meta-analyses of the studies reviewed by the USPSTF [US Preventive Services Task Force], there were no differences between PrEP and placebo or no PrEP in risk of syphilis ( 4 trials; RR, 1.08 [95\% Cl, 0.98 to 1.18$]$ ), gonorrhea (5 trials; RR, 1.07 [0.82 to 1.39 ]), chlamydia ( 5 trials; RR, 0.97 [o.80 to $1.18]$ ), or combined bacterial STIs (2 trials; RR, 1.14 [0.97 to 1.34 ])."17

\section{Circumcision to prevent HIV infection}

- "To date, there is little evidence from the few studies available of either unsafe practices or reported increases in risky behaviour" 18

\section{HPV vaccination to prevent cervical cancer}

- "The consistent, replicated evidence found across the 20 studies examined in this systematic review 
provides a strong body of evidence refuting that there is an association between HPV [human papillomavirus] vaccination and risky sexual behaviour" 19

In general, risk compensation is more likely to be reported in observational rather than experimental studies (that is, in studies at higher risk of bias). For example, a review of HIV pre-exposure prophylaxis based on observational studies reported evidence of risk compensation, ${ }^{20}$ whereas a more recent review based on randomised trials did not. ${ }^{17}$

Driver safety remains one of the most contested areas regarding the existence of risk compensation. However, most studies are observational, and robust evidence synthesis is lacking. The evidence that rates of crashes and deaths have declined steadily over decades has yet to be squared with accounts of riskier driving behaviours as safety measures have been introduced..$^{12}$ A more parsimonious account is one that considers behavioural responses to safety measures as part of a wider system of behavioural adaptation. In this scenario partial but not complete risk compensation might occur under some conditions. ${ }^{14}$

\section{Face coverings and respiratory infections}

At least 22 systematic reviews have assessed the effect of wearing a mask on transmission of respiratory virus infections. ${ }^{61-41}$ These included six experimental studies conducted in community settings that measured hand hygiene. One of these assessed the use of face masks for managing viral respiratory infections ${ }^{42}$ and the remaining five for managing influenza specifically. ${ }^{43-47}$ Wearing masks did not reduce the frequency of hand washing or hand sanitising in any of the six studies (table 1). Indeed, in two studies, self-reported rates of hand washing were higher in the groups allocated to wearing masks. 4244

Table 1 | Effect of wearing face masks on hand hygiene in a community setting for managing the spread of respiratory viral infections

\begin{tabular}{lcc} 
& & Effect on hand hygiene \\
\cline { 2 - 3 } Study & Hand washing & Sanitiser use \\
\hline Alfelali $2019^{42}$ & + & 0 \\
\hline Aiello $2012^{43}$ & + & Not reported \\
\hline Cowling $2008^{44}$ & 0 & 0 \\
\hline Cowling $2009^{45}$ & Not assessed & 0 \\
\hline Larson $2010^{46}$ & 0 & Not assessed
\end{tabular}

See supplementary file on bmj.com for details of the studies.

$+=$ Increased hand hygiene, $0=$ no effect. No studies reported a decrease (risk compensation).

All six studies were cluster randomised controlled trials and included a total of 2042 households, student residences, or Hajj tents in Hong Kong, the United States, Thailand, and Saudi Arabia..$^{42-47}$ All included a non-intervention group. Two studies included an intervention group comprising face masks only, 4244 in which participants were provided with masks and instructed on their use. Three studies included an intervention that combined masks with a hand hygiene intervention, in which participants were provided with liquid hand soap or hand sanitiser and instructed on use. ${ }^{45-47}$ One study included two face mask groups, one with and one without a hand hygiene intervention. 43

Hand hygiene was measured using a mixture of self-report and volumes of soap or hand sanitiser provided as part of the study. Four studies measured soap volume, ${ }^{45-47}$ and all six used self-reported measures, including frequency of hand washing and hand sanitising. The studies were designed to assess the effect of wearing masks and hand hygiene on rates of respiratory viral infection. None was designed to assess risk compensation.

None of the 22 systematic reviews of the effect of wearing a mask on respiratory virus infections included studies that assessed physical or social distancing. Through additional searches, we found three observational studies that had not been peer reviewed. These assessed the effect of mask wearing on the behaviour of others, as opposed to that of the mask wearer, ${ }^{48-50}$ and all observed that people moved away from those wearing a mask. While of interest, such studies do not provide evidence to judge risk compensation by the wearer of the mask.

\section{Understanding interactions between protective behaviours}

The idea of risk compensation may appeal to some as an example of the oddities of human behaviour. But it can be used to stop potentially effective interventions about which people hold strong views, by arguing that an intervention might be worse for a population than no intervention. There is, however, no compelling evidence that such risk compensation exists at a population level.

We do not rule out the possibility that for some people, engaging in one behaviour can influence other behaviours in ways that might attenuate their beneficial effects. But based on the evidence we review here, any attenuation is unlikely to be sufficient to counter, or even reverse, these beneficial effects and lead to a worse outcome for a population.

Aside from risk compensation, two other outcomes are possible from wearing a face covering or engaging in some other protective behaviour. Firstly, there may be no effect. This can occur if two or more behaviours, originally motivated by the same goal, become routine and are activated by different cues. For example, if wearing a face covering is cued by a sign at the entrance to a train station whereas hand washing is cued by seeing a hand sanitiser.

Secondly, people who engage in one protective behaviour may become more likely, rather than less likely, to engage in related behaviours. This can occur if protective behaviours also serve as cues to initiate other protective behaviours. For example, if wearing a face covering acts as a cue to wearers or observers to maintain a safe physical distance. ${ }^{51}$ 
The conditions under which any of these outcomes occurs-no effect, an increase, or a decrease in other behaviours-and how this might vary across behaviours and threats, between individuals, cultures and contextual cues, is unknown but knowable. Dropping the imprecisely used term risk compensation-with its unfounded theoretical and empirical basis-and replacing it with more meaningful terms within an approach grounded in contemporary behavioural science would do much to advance this quest. ${ }^{52}$

\section{Laying the theory to rest}

Evidence is growing that wearing face covering reduces the spread of SARS-CoV-2, and the limited evidence available does not support concerns that their use adversely affects hand hygiene. This is in keeping with the larger body of evidence on interventions for which risk compensation has been shown to be an unfounded concern. Studies are still warranted to understand how people behave when wearing face coverings in different types of shared indoor spaces, observing not only hand hygiene but also physical distancing in both the wearers and others. Critically, these studies should be designed to evaluate how space is most effectively designed to maximise behaviours that reduce transmission of SARS-CoV-2. Such studies will also provide a context to assess how these behaviours interact, to lay to rest risk compensation as an outcome of wearing face coverings.

In 2016, Pless ${ }^{12}$ argued that risk compensation theory "is a dead horse that no longer needs to be beaten." We would add that this dead horse now needs burying to try to prevent the continued threat it poses through slowing the adoption of effective public health interventions.

\section{Key messages}

- Risk compensation-increasing risky behaviour after adopting a protective measure-has been used to argue against public health interventions, such as face coverings to reduce transmission of SARS-CoV-2

- Available evidence does not support concerns that wearing face coverings adversely affects hand hygiene

- Evidence from other areas also indicates that risk compensation is not discernible at a population level

- The concept of risk compensation, rather than risk compensation itself, seems the greater threat to public health through delaying potentially effective interventions

\section{Correction: This article was updated on 27 July 2020 to correct some errors in references} 1-5 and update the supplementary file.

Contributors and sources: TMM conceived the idea for this paper in discussion with GJR when reviewing evidence on possible behavioural responses of the general public to wearing face coverings during pandemics. They are both participants in the UK government's Scientific Advisory Group for Emergencies (SAGE), currently responding to the covid-19 pandemic, and two SAGE subgroups: the scientific pandemic influenza group on behaviours and the environment and modelling group. EM brought expertise in systematic literature reviewing and topic expertise on risk compensation. Details of the search strategies used for this article are available from the authors on request. TMM and EM prepared the first draft of the paper to which GJR added conceptual ideas. All authors edited the manuscript before approving the final version. TMM is guarantor of the article.

Competing interests: We have read and understood BMJ policy on declaration of interests and declare EM is funded by a National Institute for Health Research (NIHR) senior investigator award held by TMM. GJR was funded by the NIHR Health Protection Research Unit in Emergency Preparedness and Response, a partnership between Public Health England, King's College London, and the University of East Anglia. The views expressed are those of the authors and not necessarily those of the NIHR, Public Health England, or the Department of Health and Social Care.

Provenance and peer review: Not commissioned; externally peer reviewed.
Royal Society. Face masks and coverings for the general public: behavioural knowledge

effectiveness of cloth coverings and public messaging. 2020. https://royalsociety.org///media/policy/projects/set-c/set-c-facemasks.pdf?la=en-

GB\&hash=A22A87CB28F7D6AD9BD93BBCBFC2BB24

2 Brauner JM, Mindermann S, Sharma M, et al. The effecrtiveness of eight nonpharmaceutical interventions against covid-19 in 41 countries. MedRxiv 2020.05.28.2011512 [Preprint.] doi: 10.1101/2020.05.28.2011612

3 Mitze T, Kosfeld R, Rode J, et al. Face masks considerably reduce covid-19 cases in Germany: a synthetic control method approach. IZA Institute, 2020. https://www.iza.org/publications/dp/13319/face-masks-considerably-reduce-covid-19-cases-in-germany-a-synthetic-controlmethod-approach

Payne DCS-JS, Nowak G, Chukwuma U, et al. SARS-CoV-2 infections and serologic responses from a sample of US Navy service members-USS Theodore Roosevelt. 2020. https:/www.cdc.gov/mmwr/volumes/69/wr/mm6923e4.htm

5 Hendrix MJ, Walde C, Findley K, Trotman R. Absence of apparent transmission of SARS-CoV-2 from two stylists after exposure at a hair salon with a universal face covering policy-Springfield, Missouri, May 2020. MMWR Morb Mortal Wkly Rep 2020;69:930-2.

doi: 10.15585/mmwr.mm6928e2 pmid: 32673300

6 Greenhalgh T, Schmid MB, Czypionka T, Bassler D, Gruer L. Face masks for the public during the covid-19 crisis. BMJ2020;369(m1435):m1435. doi: 10.1136/bmj.m1435 pmid: 32273267

Martin G, Hanna E, Dingwall R. Face masks for the public during Covid-19: an appeal for caution in policy. SocArXiv, 25 Apr 2020 [Preprint.] doi: 10.31235/osf.io/uyzxe

8 World Health Organization. Advice on the use of masks in the context of covid-19: interim guidance. 5Jun 2020. https://www.who.int/publications-detail/advice-on-the-use-of-masks-in-the-community-during-home-care-and-in-healthcare-settings-in-the-context-of-the-novel-coronavirus-(2019ncov)-outbreak

9 European Centre for Disease Prevention and Control. Using face masks in the community-reducing covid-19 transmission from potentially asymptomatic or pre-symptomatic people through the use of face masks. 2020. https://www.ecdc.europa.eu/en/publications-data/using-face-masks-community-reducing-covid-19-transmission

10 Lazzarino Al, Steptoe A, Hamer M, Michie S. Covid-19: important potential side effects of wearing face masks that we should bear in mind. BMJ2020;369(m1435):m2003. doi: 10.1136/bmj.m2003 pmid: 32439689

11 SAGE. SPI-B return to SAGE on the use of facemasks in a community setting. 2020. https://assets.publishing.service.gov.uk/government/uploads/system/uploads/attachment_data/file/888572/4C._200420_SPI-B_return_to_SAGE_CMO_on_facemasks_FINAL_S0208.pdf

12 Pless B. Risk compensation: revisited and rebutted. Safety2016;2:16. doi: 10.3390/safety2030016

13 Peltzman S. The effects of automobile safety regulation. J Polit Econ 1975;83:677-725doi: 10.1086/260352

14 Hedlund J. Risky business: safety regulations, risks compensation, and individual behavior. Inj Prev 2000;6:82-90. doi: 10.1136/ip.6.2.82 pmid: 10875661

15 Esmaeilikia M, Radun I, Grzebieta R, etal. Bicycle helmets and risky behaviour: A systematic review. Transp Res, Part F Traffic Psychol Behav2019;60:299-310doi: 10.1016/j.trf.2018.10.026.

16 Haider AH, Saleem T, Bilaniuk JW, Barraco RDEastern Association for the Surgery of Trauma Injury ControlViolence Prevention Committee. An evidence-based review: efficacy of safety helmets in the reduction of head injuries in recreational skiers and snowboarders. J Trauma Acute Care Surg 2012;73:1340-7. doi: 10.1097/TA.0b013e318270bbca pmid: 23117389

17 Owens DK, Davidson KW, Krist AH, etalUS Preventive Services Task Force. Preexposure prophylaxis for the prevention of HIV infection: US Preventive Services Task Force recommendation statement. JAMA 2019;321:2203-13. doi: 10.1001/jama.2019.6390 pmid: 31184747

18 Weiss HA, Dickson KE, Agot K, Hankins CA. Male circumcision for HIV prevention: current research and programmatic issues. AIDS 2010;24(Suppl 4):S61-9. doi: 10.1097/01.aids.0000390708.66136.f4 pmid: 21042054

19 Kasting ML, Shapiro GK, Rosberger Z, Kahn JA, Zimet GD. Tempest in a teapot: a systematic review of HPV vaccination and risk compensation research. Hum Vaccin Immunother 2016;12:1435-50. doi: 10.1080/21645515.2016.1141158 pmid: 26864126

20 Traeger MW, Schroeder SE, Wright E), etal. Effects of pre-exposure prophylaxis for the prevention of HIV infection on sexual risk behavior in men who have sex with men: a systematic review and meta-analysis. Clin Infect Dis 2018;67:676-86. doi: 10.1093/cid/ciy182 pmid: 29509889

21 Jefferson T, Del Mar C, Dooley L, etal. Physical interventions to interrupt or reduce the spread of respiratory viruses: systematic review. BM/2009;339:b3675. doi: 10.1136/bmj.b3675 pmid: 19773323

22 Jefferson T, Del Mar CB, Dooley L, etal. Physical interventions to interrupt or reduce the spread of respiratory viruses. Cochrane Database Syst Rev 2011;(7):. doi: 10.1002/14651858.CD006207.pub4 pmid: 21735402

23 Bin-Reza F, Lopez Chavarrias V, Nicoll A, Chamberland ME. The use of masks and respirators to prevent transmission of influenza: a systematic review of the scientific evidence. Influenza Other Respir Viruses 2012;6:257-67. doi: 10.1111/j.1750-2659.2011.00307.x pmid: 22188875

24 Perski O, Simons D, West R, etal. Face masks to prevent community transmission of viral respiratory infections: A rapid evidence review using Bayesian analysis. Qeios, 2020, doi: $10.32388 / 1 S C 5 L 4$ 
25 Xiao J, Shiu EYC, Gao H, etal. Nonpharmaceutical measures for pandemic influenza in nonhealthcare settings - personal protective and environmental measures. Emerg Infect Dis 2020;26:967-75. doi: 10.3201/eid2605.190994 pmid: 32027586

26 Brainard JS, Jones N, Lake I, et al. Facemasks and similar barriers to prevent respiratory illness such as COVID-19: A rapid systematic review. medRxiv 2020.04.01.20049528 [Preprint.] doi: 10.1101/2020.04.01.20049528

27 Howard J, Huang A, Li Z, etal. Face masks against COVID-19: an evidence review. Preprints 2020;2020040203. doi: 10.20944/preprints202004.0203.v1

28 Maclntyre CR, Chughtai AA. A rapid systematic review of the efficacy of face masks and respirators against coronaviruses and other respiratory transmissible viruses for the community, healthcare workers and sick patients. Int J Nurs Stud 2020;108:

doi: 10.1016/j.jinurstu.2020.103629 pmid: 32512240

29 Marasinghe KM. A systematic review investigating the effectiveness of face mask use in limiting the spread of COVID-19 among medically not diagnosed individuals: shedding light on current recommendations provided to individuals not medically diagnosed with COVID-19. Prev Med Infect Dis [Preprint.] doi: 10.21203/rs.3.rs-16701/v1

30 Long Y, Hu T, Liu L, etal. Effectiveness of N95 respirators versus surgical masks against influenza: A systematic review and meta-analysis. J Evid Based Med 2020;13:93-101. doi: 10.1111/jebm.12381 pmid: 32167245

31 Goeijenbier M, van Genderen P, Ward BJ, Wilder-Smith A, Steffen R, Osterhaus AD. Travellers and influenza: risks and prevention. J Travel Med 2017;24:. doi: 10.1093/jtm/taw078 pmid: 28077609

32 Barasheed O, Alfelali M, Mushta S, etal. Uptake and effectiveness of facemask against respiratory infections at mass gatherings: a systematic review. Int I Infect Dis 2016;47:105-11. doi: 10.1016/j.ijid.2016.03.023 pmid: 27044522

33 MacIntyre CR, Chughtai AA. Facemasks for the prevention of infection in healthcare and community settings. BMJ 2015;350:h694. doi: 10.1136/bmj.h694 pmid: 25858901

34 Smith SM, Sonego S, Wallen GR, Waterer G, Cheng AC, Thompson P. Use of non-pharmaceutical interventions to reduce the transmission of influenza in adults: A systematic review. Respirology 2015;20:896-903. doi: 10.1111/resp.12541 pmid: 25873071

35 Lam W, Dawson A, Fowler C. Health promotion interventions to prevent early childhood human influenza at the household level: a realist review to identify implications for programmes in Hong Kong. J Clin Nurs 2015;24:891-905. doi: 10.1111/jocn.12646 pmid: 24964081

36 Saunders-Hastings P, Crispo JAG, Sikora L, Krewski D. Effectiveness of personal protective measures in reducing pandemic influenza transmission: A systematic review and meta-analysis. Epidemics 2017;20:1-20. doi: 10.1016/j.epidem.2017.04.003 pmid: 28487207

37 Cowling BJ, Zhou Y, Ip DK, Leung GM, Aiello AE. Face masks to prevent transmission of influenza virus: a systematic review. Epidemiol Infect 2010;138:449-56. doi: 10.1017/S0950268809991658 pmid: 20092668

38 Chu DK, AkI EA, Duda S, Solo K, Yaacoub S, Schünemann HJCOVID-19 Systematic Urgent Review Group Effort (SURGE) study authors. Physical distancing, face masks, and eye protection to prevent person-to-person transmission of SARS-CoV-2 and COVID-19: a systematic review and meta-analysis. Lancet2020;395:1973-87. . doi: 10.1016/S0140-6736(20)31142-9 pmid: 32497510

39 Aggarwal N, Dwarakanathan V, Gautam N, Ray A. Facemasks for prevention of viral respiratory infections in community settings: a systematic review and meta-analysis. Indian J Public Health 2020;64(Suppl):S192-200. doi: 10.4103/ijph.JPH_470_20 pmid: 32496254

40 Liang M, Gao L, Cheng C, etal. Efficacy of face mask in preventing respiratory virus transmission: A systematic review and meta-analysis. Travel Med Infect Dis 2020;101751: doi: 10.1016/j.tmaid.2020.101751 pmid: 32473312

41 Juneau C-E, Pueyo T, Bell M, et al. Evidence-based, cost-effective interventions to suppress the COVID-19 pandemic: a rapid systematic review. medRxiv 2020.04.20.20054726 [Preprint.] doi: 10.1101/2020.04.20.20054726

42 Alfelali M, Haworth EA, Barasheed O, et al. Facemask versus no facemask in preventing viral respiratory infections during hajj: a cluster randomised open label trial. SSRN 2019. [Preprint.] https://papers.ssrn.com/sol3/papers.cfm?abstract_id=3349234

43 Aiello AE, Perez V, Coulborn RM, Davis BM, Uddin M, Monto AS. Facemasks, hand hygiene, and influenza among young adults: a randomized intervention trial. PLoS One 2012;7:. doi: 10.1371/journal.pone.0029744 pmid: 22295066

44 Cowling BJ, Fung RO, Cheng CK, etal. Preliminary findings of a randomized trial of non-pharmaceutical interventions to prevent influenza transmission in households. PLoS One 2008;3:. doi: 10.1371/journal.pone.0002101 pmid: 18461182

45 Cowling BJ, Chan K-H, Fang VJ, etal. Facemasks and hand hygiene to prevent influenza transmission in households: a cluster randomized trial. Ann Intern Med 2009;151:437-46. doi: 10.7326/0003-4819-151-7-200910060-00142 pmid: 19652172

46 Larson EL, Ferng Y-H, Wong-McLoughlin J, Wang S, Haber M, Morse SS. Impact of non-pharmaceutical interventions on URIs and influenza in crowded, urban households. Public Health Rep 2010;125:178-91. doi: 10.1177/003335491012500206 pmid: 20297744

47 Simmerman JM, Suntarattiwong P, Levy J, etal. Findings from a household randomized controlled trial of hand washing and face masks to reduce influenza transmission in Bangkok, Thailand. Influenza Other Respir Viruses 2011;5:256-67. doi: 10.1111/j.1750-2659.2011.00205.x pmid: 21651736

48 Marchiori M. COVID-19 and the social distancing paradox: dangers and solutions. arXiV 2020;2005.12446 [Preprint.] 2020. doi: arXiv:2005.12446

49 Seres GA, Balleyer N. Cerutti A, et al. Face masks increase compliance with physical distancing recommendations during the covid-19 pandemic. OSF 2020 [Preprint.] osf.io/db8s]
50 Seres G, Balleyer AH, Cerutti N, et al. Face mask use and physical distancing before and after mandatory masking: Evidence from public waiting lines. [Preprint.] SSRN2020 https://papers.SS rn.com/sol3/papers.cfm?abstract_id=3641367

51 Cialdini RB, Goldstein NJ. Social influence: compliance and conformity. Annu Rev Psychol 2004;55:591-621. doi: 10.1146/annurev.psych.55.090902.142015 pmid: 14744228

52 Hagger MS, Cameron LD, Hamilton K, etal, eds. The handbook of behavior change. Cambridge University Press, (forthcoming) doi: 10.1017/9781108677318

This article is made freely available for use in accordance with BMJ's website terms and conditions for the duration of the covid-19 pandemic or until otherwise determined by BMJ. You may use, download and print the article for any lawful, non-commercial purpose (including text and data mining) provided that all copyright notices and trade marks are retained. 